\title{
Acute Toxicity of Seleniferous Pleurotus Geesteranus Mycelia and Antioxidation against D-galactose-induced Mice
}

\author{
Jun-chen CHEN ${ }^{1}$, Li WU ${ }^{2}$, Heng-sheng SHEN ${ }^{3, *}$, Min-jie WENG ${ }^{4}$ \\ and Pu-fu LAI ${ }^{5}$ \\ 1,2,3,4,5 Research Institute of Agri-engineering Technology, Fujian Academy of \\ Agricultural Sciences, Fuzhou 350003, P. R. China \\ ${ }^{*}$ Corresponding author
}

Keywords: Seleniferous mushroom, Pleurotus geesteranus singer, Antioxidant, Acute toxicity, Mouse.

\begin{abstract}
Liquid culture of seleniferous mycelia of Pleurotus geesteranus Singer (SeMyc-P) was evaluated for its acute toxicity in supplement application and antioxidant against D-galactose induced oxidation damaged mice. Maximum Tolerant Dose (MTD) of SeMyc-P was about $20 \mathrm{~g} / \mathrm{kg}$ bw for mice to define safety application for selenium supplement against acute toxicity. Comparing with carboxymethyl cellulose sodium (CMC) control and VitE standard group, SeMyc-P in 10-days administration increased blood GSH-Px about 24.8-52.0\% and 17.1-42.6\%, respectivily. By 45-days administration against D-galactose induced oxidative stress mice, the optimal given level of SeMyc-P was $0.2 \mu \mathrm{g} / \mathrm{hd} / \mathrm{d}$ equivalent to 5-times of DRIs in selenium for Recommended Nutritional Intake $(\mathrm{RNI}=50 \mu \mathrm{g} / \mathrm{d})$, which increased blood GSH-Px $18.48 \%$ than CK-m group concomitant with decreasing MDA and protein carbonyl for $22.19 \%$ and $44.16 \%$, respectively.
\end{abstract}

\section{Introduction}

Selenium is an essential trace mineral in micronutrient for organisms with important antioxidant function as the constituent of glutathione peroxidase (GSH-Px). The functions and mechanisms of Se-dependant GSH-Px in maintaining human health and strengthening life have been studied and reviewed intensively [1-6], especially in antioxidant activity for aging defending, against cardiovascular diseases and cancers such as lung tumor [7], uterine cervix [8] and prostate cancers [9]. The trace but essential of selenium in nutrition indicates that either overdose or insufficiency of dietary selenium might result in harmful risk. Two extremely cases been recorded in last eighties, endemic selenium intoxication is resulting of rich in selenium geographical storage in Enshi of Hubei [10, 11], while endemic diseases Keshan and Kaschin-Beck are selenium deficiency found in a very broad belt stretching from Heilongjiang in northeast to Yunnan in southwest of China [3, 12, 13]. Accordingly, China has been described in scarcity of selenium sources but with variation in geographical distribution of selenium existing [3, 10, 14]. This selenium deficient belt leads to insufficient selenium content of agricultural products in such region. Since then, the attention has been given to searching effective solution for overcoming this dietary selenium insufficiency $[3,12,13,15,16]$.

Despite the food/feed additive that sodium selenite is allowable, the most preferable approach for making seleniferous additive is through biotransformation of inorganic selenite into organic seleniferous products, such as seleniferous plants, animals or microorganisms. Comparatively, the approach of culturing microorganism like edible 
fungi or yeast with Se-enriched medium has performed more efficacious than it of cropping plants and feeding animals for producing organic seleniferous products [17-20]. This is due to fungal characters in quick growth, short life time and efficient metabolism especially in biotransformation of inorganic elements. Moreover, it has been confirmed that seleniferous mushroom additives are also beneficial in improving selenium bioavailability [21] and concomitant with strengthening in immunity for consumers [8]. By in vivo model, the selenium-enriched mushrooms stimulate GSH-Px activities in antioxidant and antitumor more effective than it of sodium selenite dose [7, 8].

The efficiency in selenium enrichment with mushrooms biotransformation is biologically relative to the threshold limit value in selenium for different mushroom species $[19,22-24]$ in addition to varying of bioavailability against selenium sources, such as wheat bran enforced sodium selenite [20], wheat straw harvested from seleniferous region [17] and coffee rusk enforced sodium selenite [21]. The tolerance level of Pleurotus geesteranus mycelium against Se element in Sodium selenite has been confirmed around 3-5 $\mu \mathrm{g} / \mathrm{g}$ or $\mu \mathrm{g} / \mathrm{ml}$, which enhances growth for seleniferous mycelium significantly $[19,20]$. However, the seleniferous products of $P$. geesteranus liquid culture are requested further in defined for its antioxidant activity and acute toxicity to satisfy in practical and safety application. This paper has summarized the results of in vivo evaluation for seleniferous $P$. geesteranus mycelium products (SeMyc-P), including: the safety in use it for dietary se-supplement defined with acute toxicity assay for Maximum Tolerated Dose (MTD, g per kg body weight); the capacity in antioxidant and its protective function against D-galactose induced oxidative stress for mice. Although the physiological mechanisms of selenium bioactive function in relation to health strength has been studied extensively, the current in vivo assessments attempt to demonstrate the safety issue and practical availability of Se-enriched $P$. geesteranus mycelium products as food ingredients against induced oxidative stress to daily life of mice.

\section{Materials and Methods}

\section{Seleniferous Culture of $\boldsymbol{P}$. geesteranus}

Seleniferous culture products of $P$. geesteranus were provided by Functional Food Research Group in Fujian Academy of Agricultural Sciences, Fujian China. The seleniferous liquid culture was conducted according to the procedure described by Shen et al. [19] and with modification in Se-enforced liquid culture mediums by adding sodium selenite twice: in $1 \mathrm{mg} / \mathrm{L}$ first for preparing inoculation suspension; then in $3 \mathrm{mg} / \mathrm{L}$ to culture medium for seleniferous mycelium growth. At culture completed, $P$. geesteranus mycelia were separated from spent liquid medium by centrifugation, and products of seleniferous mycelia (SeMyc) and spent medium (SeMed) were obtained through freeze drying and spray drying, respectively. The whole liquid culture product of seleniferous $P$. geesteranus (SeMyc-P) was also processed with freeze drying but not separating seleniferous mycelia from spent medium. Total Se content of SeMyc-P, SeMyc and SeMed was 46.95, 42.97 and $8.62 \mathrm{mg} / \mathrm{kg}$, respectively, in dry substance base.

\section{Acute Toxicity Assay}

To define the safety in seleniferous metabolites and/or free inorganic se element if existed in any, the SeMed and SeMyc were used for intragastrical administration. 
Based on the previous knowledge in the safety of $P$. geesteranus mycelium metabolites and the selenium level used in mushroom liquid culture, the safety of the products against selenium acute toxicity was defined in term of MTD (Maximum Tolerant Dose). Forty ICR mice (20 males and 20 females) in $18 \pm 2 \mathrm{~g}$ average body weight (bw) were purchased (SCXK (Hu) 2007-0005), mouse's feed (Hu Feed Inspection (2008) 04002) provided meantime. The acute toxicity assay was conducted by Fujian Center for Disease Control and Prevention (SYXK (Min) 2012-0008), China. The maximum for administration by gavage was based on body weight of mouse for $20 \mathrm{~g} / \mathrm{kg}$ bw in product weight and $20 \mathrm{ml} / \mathrm{kg}$ bw in solution volume, by which the selenium content of SeMed and SeMyc given to mice were equivalent to 172 and $859 \mu \mathrm{g} / \mathrm{kg}$ bw, respectively. Dietary Recommended Indices (DRIs) issued by Chinese Nutrition Society [25] in selenium for Recommended Nutritional Intake (RNI) is $50 \mu \mathrm{g} / \mathrm{d}$ for adult with $50 \mathrm{~kg}$ average bw, while Recommended Dietary Allowances (RDA) issued by National Institutes of Health, US [26] in Selenium is $55 \mu \mathrm{g} / \mathrm{d}$ for adult with $55 \mathrm{~kg}$ average bw. Based on DRIs in Selenium RNI for adult, the administration dose of tested products in $\mu \mathrm{g} / \mathrm{d}$ for per $\mathrm{kg}$ bw was higher than hundreds of selenium in RNI given by DRIs. Given samples of SeMyc and SeMed were grinded to pass through 100-mesh and dissolved with distilled water, respectively. After three days for adaption, forty mice were divided into two groups with same number in gender, then starved for $16 \mathrm{hrs}$ with drink water permitted before intragastric force-feed. Thereafter, dissolved sample was given to various mouse by three times divided in 4-hrs intervals, and then, the mice were set free in cage for 14-days, their eating, behaviour and toxicity symptom were recorded.

\section{In Vivo Antioxidant Capacity}

Whole liquid culture product of seleniferous $P$. geesteranus (SeMyc-P) was including seleniferous mycelia and spent medium consisting of extracellular se-dependent or non-se- metabolites and residual nutrients. For comprehensively interpreting in vivo antioxidant capacity, SeMyc-P was given daily to mice for a 10 -days period. Three selenium doses in $0.1,0.2$ and $0.4 \mathrm{mg} / \mathrm{kg}$ ration and given by $6 \mathrm{~g} / \mathrm{hd} / \mathrm{d}$ of ration were used in calculation for total se given and converted into relative amount of SeMyc-P for gavage daily. The SeMyc-P grinded to pass through 100-mesh was dissolved with carboxymethyl cellulose sodium (CMC) $0.5 \%$ and given to mouse in maximal volume by $20 \mathrm{ml} / \mathrm{kg}$ bw. Thirty male ICR mice in $22 \pm 1 \mathrm{~g}$ average bw were purchased (SCXK (Min) 2012-0001) and divided randomly into five groups to accept treatments respectively in: CMC $0.5 \%$ as solvent control (CK); VitE $50 \mathrm{mg} / \mathrm{kg}$ bw as antioxidant control $(\mathrm{CK}+)$; three SeMyc-P given dosages as Se-0.1; Se-0.2 and Se-0.4, respectively. The administration was taken daily after 3-days for adjustment accommodation. The mouse behaviours were observed and body weight was recorded at before, middle and end of gavage period. The blood serum was collected after one hour completed last gavage and tested for superoxide dismutase (SOD), glutathione peroxidase (GSH-Px), total antioxidant capacity (TAOC) and malondialdehyde (MDA) contents.

\section{Protective Effect against D-Galactose-Induced Oxidative Stress}

Fifty male ICR mice in 23 $\pm 2 \mathrm{~g}$ average bw were purchased (SCXK (Min) 2012-0001). Forty of the mice were given D-galactose by intraperitoneal injection in $400 \mathrm{mg} / \mathrm{kg} \mathrm{bw}$, once a day for 8-weeks, to induce oxidative damage model; while another 10 mice were injected physiological saline in similar dose as control group (CK). At end of inducing period, the forty mice were regrouped randomly into four: three groups accepting SeMyc-P treatments in selenium of 0.04 (L-Se), $0.2(\mathrm{M}-\mathrm{Se})$ and $0.32(\mathrm{H}-\mathrm{Se}) \mu \mathrm{g} / \mathrm{hd} / \mathrm{d}$, respectively; one group for model control (CK-m). Based on RDA in Selenium 55 $\mathrm{g} / \mathrm{d}$ 
for adult and the average bw of mice in $40 \mathrm{~g}$ per head, the amount of SeMyc-P given to mouse was calculated by converting Se treatment dose equal to it contained in SeMyc-P and was adjusted weekly according to mouse growth. The procedure of preparing SeMyc-P for administration was similar to that used for in vivo antioxidant capacity assay (in section of 2.3) and given to mouse in maximal volume by $20 \mathrm{ml} / \mathrm{kg} \mathrm{bw}$. Mice in two control groups (CK and $\mathrm{CK}-\mathrm{m}$ ) were given $0.5 \% \mathrm{CMC}$ in similar volume as SeMyc-P treatment groups. The SeMyc-P treatments taken for 45-days, meantime D-galactose intraperitoneal injection was constantly given to mice. During the experiment, mouse blood serum was collected twice from orbital veniplex at end of inducing model period and gavage period, respectively. First sampling was only for testing MDA content to ensure oxidant damaged model successfully induced comparing with $\mathrm{CK}$, while second one was for testing the content of GSH-PX, reduced glutathione (GSH), MAD and protein carbonyl (Prot-CO).

\section{Blood Analysis}

The analyses for blood serum were conducted by Nanjing Jiancheng Bioengineering Institute (Nanjing, China). Detection kits were purchased (Nanjing Jiancheng Yuehao Sci. \& Tech. Ltd. Co. China) specifically for testing blood in TAOC, SOD, GSH-Px, GSH, MAD and Prot-CO; the analytic instruction was included in each kit.

\section{Statistic Analysis}

SPSS software (version 11.5.) was performed in statistical analysis. All values were presented as mean $\pm \mathrm{SE}$ and $\mathrm{T}$-test used to compare differences between treatments and control group, respectively, with significant level at $P<0.05$.

\section{Results and Discussion}

\section{Acute Toxicity of Seleniferous $\boldsymbol{P}$. geesteranus Products}

Experimental mice, who taken over 100-times of DRIs in senilum converted on Se contained in SeMyc and SeMed, performed normally in behavior and growth without mortality or any toxicity suffering observed (Table 1). The selenium content of given SeMed and SeMyc was 172 and $859 \mu \mathrm{g} / \mathrm{kg}$ bw, respectively, in hundred-times higher than it of DRIs in RNI for adult based on body weight in $\mathrm{kg}(1 \mu \mathrm{g} / \mathrm{d} / \mathrm{kg}$ bw $)$ and about 20-times higher than it of tolerable Upper Level (UL, $400 \mu \mathrm{g} / \mathrm{d}$ ) in selenium ingested (8 $\mu \mathrm{g} / \mathrm{d} / \mathrm{kg} \mathrm{bw}$ ) as well [25]. According to the data, the dosage of SeMed and SeMyc given in $20.00 \mathrm{~g} / \mathrm{kg}$ bw was defined as maximum tolerant dose (MTD) that been interpreted as no acute toxicity of tested seleniferous $P$. geesteranus culture products and safety in use as se-enriched mushroom food additive source. By centrifuging SeMyc away, SeMed was produced with spent seleniferous liquid culture medium. Therefore, in addition to selenium in SeMyc, selenium in SeMed contributed from extracellular metabolites of selenium-dependant and/or complex selenium-compounds, and the residual free $\mathrm{Se}$ element might also be possible existed as well. The safety of both SeMyc and SeMed in acute toxicity suggested that it should be positive in safety to enable whole culture of seleniferous $P$. geesteranus products (SeMyc-P) as se-enriched mushroom food additive for functional ingredients. Accordingly, the MTD for SeMyc-P could be defined in $20 \mathrm{~g} / \mathrm{kg}$ bw, equivalently given by SeMyc-P selenium in $939 \mu \mathrm{g} / \mathrm{kg}$ bw, about $95 \%$ of it was bioorganic selenium in SeMyc-P (unpublished data provided by research team). Without separating SeMyc from SeMed, SeMyc-P might perform benefits resulting of mushroom mycelia and metabolites in addition to Se supplement $[7,8]$. 
Table 1 Acute toxicity assay of seleniferous $P$. geesteranus culture products

\begin{tabular}{|c|c|c|c|c|c|c|}
\hline \multirow{2}{*}{$\begin{array}{c}\text { Sample } \\
{[\mathrm{Se}, \mathrm{mg} / \mathrm{kg}]}\end{array}$} & \multirow[t]{2}{*}{ Gender } & \multirow{2}{*}{$\begin{array}{c}\text { Se dose } \\
{[\mu \mathrm{g} / \mathrm{kg} \mathrm{bw}]}\end{array}$} & \multirow{2}{*}{$\begin{array}{c}\text { Mortality } \\
\text { [Head] }\end{array}$} & \multicolumn{2}{|c|}{$\begin{array}{c}\text { BW } \\
\text { [g/head] }\end{array}$} & \multirow{2}{*}{$\begin{array}{c}\text { MTD } \\
\text { [g/kg bw] }\end{array}$} \\
\hline & & & & Initial & Final & \\
\hline SeMyc & Male & 859 & 0 & $20.0 \pm 1.2$ & $30.9 \pm 1.9$ & $>20.00$ \\
\hline (42.97) & Female & 859 & 0 & $20.1 \pm 1.1$ & $25.8 \pm 1.0$ & $>20.00$ \\
\hline SeMed & Male & 172 & 0 & $20.1 \pm 1.2$ & $31.9 \pm 1.5$ & $>20.00$ \\
\hline$(8.62)$ & Female & 172 & 0 & $20.2 \pm 1.0$ & $26.1 \pm 0.9$ & $>20.00$ \\
\hline
\end{tabular}

Data were displayed with mean $\pm \operatorname{SE}(n=10)$.

\section{Antioxidant Capacity of SeMyc-P}

Malondialdehyde (MDA), a product of lipid peroxidation resulted in reactive oxygen species degrading polyunsaturated lipids, was measured to indicate oxidative stress resulting in mouse [27]. To determine the antioxidant effect of SeMyc-P, the content of superoxide dismutase (SOD), glutathione peroxidase (GSH-Px) and total antioxidant capacity (TAOC) in blood serum of mice were tested for indicating enzymatic and non-enzymatic activities against blood MDA in mice. The lower in blood MDA was, the better of antioxidant effect of SeMyc-P resulted. The comparison was made between blank (CMC) or standard (VitE) control groups with three SeMyc-P (L-Se, $\mathrm{M}-\mathrm{Se}, \mathrm{H}-\mathrm{Se}$ ) treatment groups (Table 2). The blood GSH-Px of mice in three SeMyc-P treated groups was significantly increased about $24.8-52.0 \%$ higher than it in CMC control group and $17.1-42.6 \%$ higher than in VitE standard group, respectivily; while the blood SOD of the mice only in M-Se and H-Se treated groups was increased for $13.3 \%$ and $24.1 \%$ higher than it in CMC control, respectivily. Similarly, total antioxidant capacity (TAOC) in the blood serum of mice from M-Se and H-Se treated groups was also increased for $68.4 \%$ and $101.2 \%$ higher than it of mice from CMC control, respectivily, which reflected the antioxidant capacity of non-enzymatic defense system concomitantly resulting of SeMyc-P. In consequences, SeMyc-P reduced blood MDA content significantly for the mice of all three treatment groups. Especially in H-Se treated group, antioxidant effect of SeMyc-P on reducing MDA content was equivalent to same effect resulting of VitE treatment. Statistical data in correlation between antioxidant indices (Table 2) indicated that antioxidant capacity of SeMyc-P consisted of enzymatic and non-enzymatic activities although SOD, GSH-Px and TAOC contributed differently in against oxidative stress for eliminating MDA products interpreted by negative correlation coefficients. SOD (Superoxide dismutase) presented more efficiency in catalyzing for deduction of MDA, followed by TAOC and GSH-Px.

Statistical data in correlation between antioxidant indices (Table 2) indicated that antioxidant capacity of SeMyc-P consisted of enzymatic and non-enzymatic compounds, of which contributed differently in eliminating MDA produced against oxidative stress interpreted by negative correlation coefficients in somewhat. SOD (Superoxide dismutase) presented more efficiency in deduction of MDA, followed by TAOC that determined antioxidation resulting of non-enzymatic and small molecular compounds. The positive correlation between enzymatic (GSH-Px) and non-enzymatic (TAOC) suggested that a synergistic effect on TAOC might be resulting of seleniferous metabolites in SeMyc-P with GSH-Px although it was assumed statistically. 
Table 2 Antioxidant indices in mice given with SeMyc-P

\begin{tabular}{|c|c|c|c|c|c|}
\hline \multirow{2}{*}{$\begin{array}{l}\text { Treatment } \\
\text { Index }\end{array}$} & \multirow{2}{*}{$\begin{array}{c}\mathrm{CMC} \\
{[0.5 \%]}\end{array}$} & \multirow{2}{*}{$\begin{array}{c}\text { Vit E } \\
{[50 \mathrm{mg} / \mathrm{kg} \mathrm{bw}]}\end{array}$} & \multicolumn{3}{|c|}{$\begin{array}{c}\text { SeMyc-P } \\
{[\mathrm{Se}=\mathrm{mg} / \mathrm{kg} \text { ration }]}\end{array}$} \\
\hline & & & $\begin{array}{c}\mathrm{L}-\mathrm{Se} \\
{[\mathrm{Se}=0.1]}\end{array}$ & $\begin{array}{c}\mathrm{M}-\mathrm{Se} \\
{[\mathrm{Se}=0.2]}\end{array}$ & $\begin{array}{c}\mathrm{H}-\mathrm{Se} \\
{[\mathrm{Se}=0.4]}\end{array}$ \\
\hline $\begin{array}{c}\text { MDA } \\
{[\mathrm{nmol} / \mathrm{ml}]}\end{array}$ & $15.40 \pm 1.12^{\mathrm{a}}$ & $9.14 \pm 1.09^{c}$ & $11.10 \pm 1.03^{\mathrm{b}}$ & $10.90 \pm 0.83^{b}$ & $8.95 \pm 1.20^{\mathrm{c}}$ \\
\hline $\begin{array}{l}\text { TAOC } \\
{[\mathrm{u} / \mathrm{ml}]}\end{array}$ & $3.33 \pm 0.65^{\mathrm{d}}$ & $4.77 \pm 0.45^{b c}$ & $3.91 \pm 0.57^{\mathrm{cd}}$ & $5.61 \pm 0.56^{\mathrm{ab}}$ & $6.74 \pm 0.74^{a}$ \\
\hline $\begin{array}{l}\text { SOD } \\
{[\mathrm{u} / \mathrm{ml}]}\end{array}$ & $198.56 \pm 11.93^{\mathrm{d}}$ & $267.70 \pm 10.68$ & $209.65 \pm 20.09^{\text {cd }}$ & $224.44 \pm 22.75 \mathrm{bc}$ & $246.44 \pm 15.96^{\mathrm{ab}}$ \\
\hline $\begin{array}{c}\text { GSH-Px } \\
{[\mathrm{u} / \mathrm{ml}]}\end{array}$ & $322.05 \pm 33.13^{\mathrm{c}}$ & $343.25 \pm 37.77^{\mathrm{c}}$ & $402.05 \pm 39.84^{b}$ & $455.38 \pm 32.59^{\mathrm{a}}$ & $489.57 \pm 49.63^{\mathrm{a}}$ \\
\hline \multicolumn{6}{|c|}{--- Correlation coefficients between MDA and antioxidant factors--- } \\
\hline & MDA & \multicolumn{2}{|c|}{ TAOC } & SOD & GSH-Px \\
\hline MDA & \multirow[t]{2}{*}{1.000} & \multicolumn{2}{|c|}{-0.549} & -0.662 & -0.382 \\
\hline TAOC & & \multicolumn{2}{|c|}{1.000} & 0.425 & 0.732 \\
\hline
\end{tabular}

Data were displayed with mean $\pm \operatorname{SE}(n=6)$, values with different superscripts in each row indicate significant differences $(\mathrm{p}<0.05)$.

\section{Protective Effect of SeMyc-P against D-galactose-induced Oxidative Stress}

D-galactose (D-gal), a reducing sugar completely metabolized in body at normal concentration, was intraperitoneal injected to mice constantly in concentration 400 $\mathrm{mg} / \mathrm{kg}$ bw once a day to induce oxidant damage for mice. Consequently, the injection resulted of increasing in blood MDA of mice for $41.9 \%$ higher in damaged model control group (CK-m) than in blank control (CK-b), so did to induce blood Prot-CO significantly higher for $51 \%$ in CK-m group than in CK-b group (Table 3). Although blood MDA content was differed individually and varied in day to day bases, the subject in use it as potential biomarker for indicating long-term oxidative stress on a group basis has been accepted generally [27]. In addition, protein carbonyl (Prot-CO) in blood serum was also measured to indicate oxidative damage in amino acid of protein for mice. Against long-term D-gal oxidative stress, SeMyc-P had been given to the oxidant damaged mice concomitantly with D-gal injection for reducing their blood MDA and Prot-CO levels. The protective effect of SeMyc-P on antioxidant activity for damaged mice was evaluated with comparison between the mice in treated groups (L-, M- \& H-Se) and in CK-m group. After applying SeMyc-P for 45-days, average blood MDA of the mice in L-Se, M-Se and H-Se groups was reduced for 20.1\%, 22.2\% and $39.3 \%$, respectively compared with it of the mice in CK-m group. Further more, the MDA content in the mice of $\mathrm{H}-\mathrm{Se}$ treated group was even lower than it of blank control group (CK-b) for $13.8 \%$. MDA reduction tendency was responded quantitatively relative to SeMyc-P given level, which meant that the higher SeMyc-P given dosage was, the greater in reducing MDA amount of mice. Similarly, giving SeMyc-P to D-gal oxidant damaged mice was also able to reduce their Prot-CO content significantly for about $38.3 \%, 44.2 \%$ and $25.3 \%$ lower in L-Se, M-Se and H-Se groups than in CK-m group, respectively. The Prot-CO content in SeMyc-P given groups was even close to it in CK-b, that result might proved the protect effect of SeMyc-P against long term exposure to oxidant stress.

Glutathione (GSH) plays important roles in antioxidant defences, nutrient metabolism, and regulation of cellular activities [28]. Interacting with glutathione peroxidise and glutathione reductase, glutathione can reduce hydrogen peroxide into 
water to protect the cell from oxidative damage. Comparing with CK-b group, mice in D-gal oxidant induced model group (CK-m) had resulted in increasing blood GSH-Px for $7.1 \%$ and decreasing GSH for $32.72 \%$ (Table 3). The observation indicated that the oxidative stress resulting of D-gal injection might stimulate mice in defensive physiological responses with interaction of GSH-Px and glutathione reductase for resisting oxidative stress. By giving SeMyc-P against continual D-gal oxidant stress, the blood GSH-Px of mice in L-Se and M-Se groups was improved for $6.14 \%$ and $18.48 \%$ than that in CK-m group, which was concomitant with GSH depression for $31.84 \%$ and $28.1 \%$, respectively in L-Se and M-Se groups that in CK-m group. There was no great changing in GSH-Px and GSH found between M-Se and H-Se groups. The optimal treating level of SeMyc-P to mice against long-term exposure of oxidative stress was observed in M-Se group, of which SeMyc-P was given by its Se content on 5-times in RDA (Se $0.2 \mu \mathrm{g} / \mathrm{hd} / \mathrm{d}$ ). Protective effect of SeMyc-P was confirmed in antioxidant function to oxidant damaged mice.

Table 3. Protective effect of SeMyc-P against oxidative damage to mice $(n=10)$

\begin{tabular}{|c|c|c|c|c|c|c|}
\hline Index & \multicolumn{2}{|c|}{$0.5 \% \mathrm{CMC}$} & \multicolumn{4}{|c|}{$\begin{array}{c}\text { SeMyc-P } \\
{[\mathrm{Se}=\mu \mathrm{g} / \mathrm{hd} / \mathrm{d}]}\end{array}$} \\
\hline & CK-b & CK-m & \multicolumn{2}{|c|}{$\begin{array}{c}\mathrm{L}-\mathrm{Se} \\
{[\mathrm{Se}=0.04]}\end{array}$} & $\begin{array}{r}\mathrm{M}-\mathrm{Se} \\
{[\mathrm{Se}=0.2}\end{array}$ & $\begin{array}{c}\mathrm{H}-\mathrm{Se} \\
{[\mathrm{Se}=0.32]}\end{array}$ \\
\hline $\begin{array}{c}\text { MDA } \\
{[\mathrm{nmol} / \mathrm{ml}]}\end{array}$ & $7.02 \pm 1.52$ & $9.96 \pm 0.76^{\mathrm{A}}$ & $7.96 \pm 1.08^{\text {в }}$ & \multicolumn{2}{|c|}{$7.75 \pm 1.19^{\mathrm{B}}$} & \\
\hline $\begin{array}{c}\text { Protein CO } \\
{[\mathrm{nmol} / \mathrm{mg}]}\end{array}$ & $1.02 \pm 0.16$ & $1.54 \pm 0.19^{\mathrm{A}}$ & $0.95 \pm 0.14^{\mathrm{B}}$ & \multicolumn{2}{|c|}{$0.86 \pm 0.10^{\mathrm{B}}$} & $1.15 \pm 0.13^{\mathrm{B}}$ \\
\hline $\begin{array}{c}\mathrm{GSH} \\
{[\mu \mathrm{mol} / \mathrm{L}]}\end{array}$ & $46.40 \pm 12.30^{\mathrm{A}}$ & $31.22 \pm 4.93$ & $21.28 \pm 5.42^{\mathrm{B}}$ & \multicolumn{2}{|c|}{$22.46 \pm 4.77^{b}$} & $23.43 \pm 4.57$ \\
\hline $\begin{array}{c}\text { GSH-Px } \\
{[\mathrm{U} / \mathrm{ml}]}\end{array}$ & $71.90 \pm 9.12$ & $77.00 \pm 12.80$ & $81.73 \pm 8.23$ & \multicolumn{2}{|c|}{$91.23 \pm 13.44^{b}$} & $91.29 \pm 10.91^{b}$ \\
\hline
\end{tabular}

Data were displayed with mean \pm SE. Values in each row with ' $A$ ' indicate differences $(p<0.01)$ between CK-b and CK-m, while with ' $b$ or B' between CK-m and treatments in $\mathrm{p}<0.05$ or $\mathrm{p}<0.01$.

\section{Effect of SeMyc-P on Mouse Growth}

Effect of SeMyc-P on mouse growth was compared in changing of body weight to confirm whether inhibiting or enhancing normal body growth by given SeMyc-P. Mice in all five groups performed similarly in the tendency of weight gain upon their physiological age (Table 4). The observation in weight gain resulting of 10-days or 45-days intragastrical administration trials agreed with the data of single administration given in acute toxicity trial as showed in Table 1 . Further more, all mice engaged in SeMyc-P administration groups were leaving normally in eating and behaviours during experiment durations no sickness symptoms observed.

Table 4. Effect of seleniferous P. geesteranus (SeMye-P) on body weight changes (g/hd)

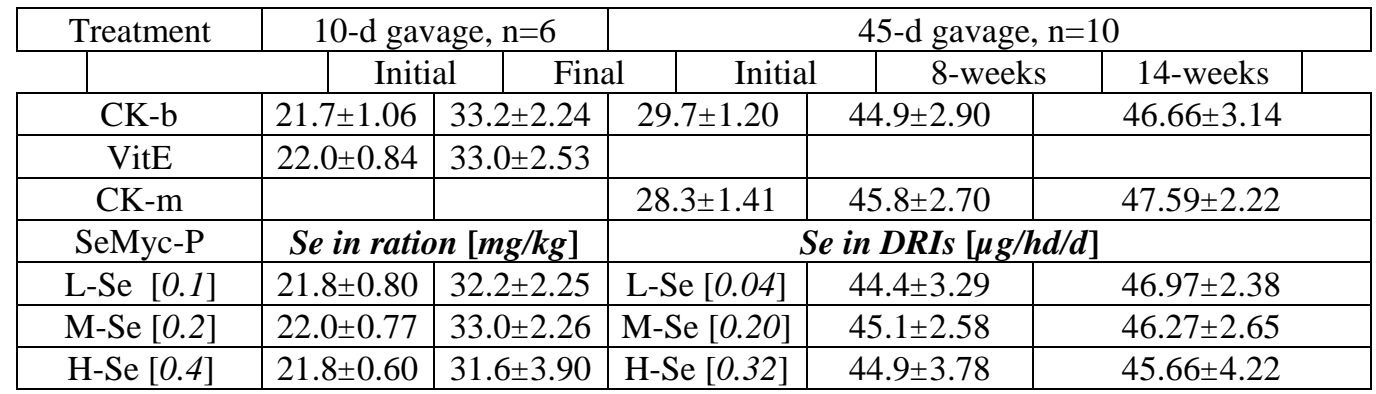

Data were displayed with mean \pm SE. 


\section{Conclusions}

Seleniferous $P$. geesteranus (SeMyc-P) was made with Se-enriched liquid culture for mycelial growth of $P$. geesteranus mushroom to obtain organic selenium-compounds enrichment through mushroom mycelium generation and metabolites. In addition to Threshold Limit Value in safety applying sodium selenite to $P$. geesteranus mushroom mycelium culture for producing SeMyc-P [19], Maximum Tolerant Dose (MTD, in >20 $\mathrm{g} / \mathrm{kg} \mathrm{bw}$ ) for the culture products (SeMyc, SeMed) to mice with intragastric administration (Table 1) determined further in safety applying the culture products for food supplement. The MTD for SeMyc and SeMed has been used for indicating MTD for SeMye-P with same culture procedure but no separation of mycelia from liquid medium. Selenium content of SeMyc-P in $20 \mathrm{~g} / \mathrm{kg}$ bw given to mice was about 939 $\mu \mathrm{g} / \mathrm{kg}$ bw and the organic selenium of it was about $95 \%$ (unpublished data provided by research team). This MTD for SeMyc-P was 100-times of selenium Intake Upper Level $(400 \mu \mathrm{g} / \mathrm{d}$ or $8 \mu \mathrm{g} / \mathrm{kg} \mathrm{bw})$ defined by DRIs [25], which suggested the benefits resulting in biotransformation of seleniferous $P$. geesteranus culture for safety application of SeMyc-P.

The antioxidant capacity of SeMyc-P has been confirmed in significantly reducing MDA of serum content attributed by SOD, TAOC and GSH-Px activities (Table 2). The significant effect of SeMyc-P for mice in three treated groups was on increasing blood GSH-Px about 24.8 - 52.0\% and 17.1 - 42.6\% higher than it in CMC control group and VitE standard group, respectivily. Its protective effect on antioxidation has also been approved for long-term application against D-galactose induced oxidative damaged mice (Table 3). Comparing with model control group (CK-m) in continual giving D-gal oxidant stress, the optimal given level of SeMyc-P was observed in M-Se group with increasing blood GSH-Px $18.48 \%$ concomitant with decreasing MDA and protein carbonyl for $22.19 \%$ and $44.16 \%$, respectively. Accordingly, this given level of SeMyc-P $(\mathrm{Se}=46.95 \mathrm{mg} / \mathrm{kg})$ in $5.32 \mathrm{~g} / \mathrm{d}$ contained Se in $250 \mu \mathrm{g} / \mathrm{d}$ about 5 -times of DRIs in RNI $(50 \mu \mathrm{g} / \mathrm{d})$. In addition, the products of SeMyc-P might also supply to mice in enriched mushroom polysaccharides and amino acids [29] except selenium element as constituent of glutathione peroxidase (GSH-Px) to benefit antioxidant function for strengthening immunity [7, 8]. Eventually, applying SeMyc-P to mice who sustained exposure in oxidative stress (CK-m) may enable SeMyc-P in synergistic activities in restoration for oxidant damaged mice back to normal as showed in blank control (CK-b). It interpreted that SeMyc-P could be safely used for Se-enriched food source although biochemical morphology of its selenium-compound was not clarified.

\section{Acknowledgments}

This work is financially supported by Special Fund for Agro-scientific Research in the Public Interest (No. 201303080).

\section{References}

[1] M.P. Bansal, P. Kaur, Selenium, Indian Journal of Experimental Biology, 43(2005) 1119-1129.

[2] British Nutrition Foundation, 2001. Biological functions of selenium. In British Nutrition Foundation (Briefing paper), Selenium and Health (pp 13-17). High Holborn House, London: www.nutrition.org.uk.

[3] H.D. Foster, Journal of Orthomolecular Medicine, 4 (1989) 123-135. 
[4] S.E. Jackson-Rosario, W.T. Self, Metallomics, 2(2010) 112-116.

[5] Y. Suzuki, Y. Hashiura, K. Matsumura, T. Matsukawa, A. Shinoharab and N. Furuta, Metallomics, 2(2010) 126-132.

[6] F. Ursini, A. Bindoli, Chemistry and Physics of Lipids, 44(1987) 255-276.

[7] H. Yan, H. Chang, Biol Trace Elem Res, 150(2012) 236-241.

[8] J. Ji, J. Liu, H. Liu and Y. Wang, Effects of fermented mushroom of Cordyceps sinensis, rich in selenium, on uterine cervix cancer. Evidence-Based Complementary and Alternative Medicine, Hindawi Publishing Corporation, (2014) 1-7.

[9] L.C. Clark, B. Dalkin, A. Krongrad, G. F. CombsJr, B. W. Turnbull, E. H. Slate, R. Witherington, J. H. Herlong, E. Janosko, D. Carpenter, C. Borosso, S. Falk and J. Rounder, British Journal of Urology, 81(1998) 730-734.

[10]G. Yang, S. Wang, R. Zhou and S. Sun, The American Journal of Clinical Nutrition, 37(1983) 872-881.

[11] Y. Huang, Q. Wang, J. Gao, Z. Lin, G.S. Banuelos, L. Yuan and X. Yin, Nutrients. 5(2013) 700-710.

[12] S. Li, T. Xiao and B. Zheng, Science of the Total Environment, 421-422(2012) 31-40.

[13]J.E. Oldfield, Selenium World Atlas, Selenium-tellurium Development Association, Information Centre: Belgium www.stda.org (2002) 42-45.

[14] L.C. Johnson, X. Ge, K.A. Green and X. Liu, Applied Geochemistry, 15(2000) $385-401$.

[15] A. Haug, R.D. Graham, O.A. Christophersen and G.H. Lyons, Microbial Ecology in Health and Disease, 19(2007) 209-228.

[16] Y. Xia, K.E. Hill, D.W. Byrne, J. Xu and R.F. Burk, Effectiveness of selenium supplements in a low-selenium area of China. American Journal of Clinic Nutrition, 81 (2005) 829-834.

[17]P. Bhatia, C. Bansal, R. Prakash and T.P. Nagaraja, Acta Alimentaria, 43(2014) 280-287.

[18]X. Gu, D. Wang, G. Wei, M. Nie and S. Na, Improvement of physiological characteristic of selenium- enriched Candida utilis with amino acids addition. Biotechnology Research International, SAGE-Hindawi Access to Research, (2011) $1-7$.

[19] H. Shen, J. Chen, B. Tang, Y. Li and L. Wu, Acta Edulis Fungi, 16 (2009) 35-38 (In Chinese).

[20]B. Tang, L. Wu, J. Chen, H. Shen and H. Zheng, Fujian Journal of Agricultural Scinces, 28(2013) 66-69 (In Chinese).

[21] M.C.S. Silva, J. Naozuka, P.V. Oliveira, M.C.D. Vanetti, D.M.S. Bazzolli, N.M.B. Costad and M.C.M. Kasuya, Metallomics, 2(2010) 162-166.

[22]Z.J. Chen, S.L. Yuan, Edible Fungi of China, 28(2009) 9-11 (In Chinese). 
[23] Y. Huang, G. Yan, G. Wang, Y. Chen and Q. Luo, Journal of Yunnan University, 19 (1997) 341-342 (In Chinese).

[24] I. Milovanovic, I. Brceski, M. Stajic, A. Korac, J. Vukojevic and A. Knezevic, The Scientific World Journal, Hindawi Publishing Corporation (2014). 1-8.

[25] Chinese Nutrition Society, Chinese DRIs Handbook. Standards Press of China, Beijing China (2013) 18-19 (In Chinese).

[26] National Institutes of Health, Selenium Dietary Supplement Fact Sheet. Department of Health and Human Services, U.S. (2013).

[27]F. Nielsen, B.B. Mikkelsen, J.B. Nielsen, H.R. Andersen and P. Grandjean, Clinical Chemistry 43(1997) 1209-1214.

[28] G. Wu, Y. Z. Fang, S. Yang, J. R. Lupton and N. D. Turner, Journal of Nutrition, 134(2004) 489-492.

[29] H. Shen, J. Chen, L. Wu, Y. Li and T. Zhou, Journal of Integrative Agriculture, 11(2012) 456-464. 